Article

\title{
Effects of Magnesium Hydroxide on Disintegration Time and Dissolution Rate of Diclofenac Sodium Plain Tablet
}

\author{
Miazi MMH ${ }^{1}$, Choudhury MMA ${ }^{2}$, Rahman $\mathrm{MH}^{3}$, Rahman $\mathrm{A}^{4}$
}

The objective of this study was to evaluate the effects of magnesium hydroxide (MH) on disintegration time (DT) and dissolution profile of diclofenac sodium (DS) plain tablet. The tablets of DS were formulated with conventionally used excipients and investigational agent $\mathrm{Mg}[\mathrm{OH}]_{2}$. Different parameters of tablets like hardness, thickness, friability, and disintegration time and dissolution rate were determined to assess the effects of $\mathrm{MH}$ on these parameters. The physical resistance against abrasion or shock of DS-MH tablets had been noticed by the results of hardness and friability test which were within the limits of standard specification. The disintegration times of tablets of the experimental batches except one, found 2.0 to 25 minutes were also within the limits of standard specification. The release rates of DS in simulated gastric fluid (SGF) at 30 minutes were inspiring about batches FO3: 84.78\% and FO4: 90.38\%. A positive correlation of coefficient determined between quantity of $\mathrm{Mg}(\mathrm{OH})_{2}$ in different batches of tablets and their effects on dissolution rate was found statistically significant $(r=0.66)$. The $t_{\max }$ of DS was not affected by the presence or increment of $\mathrm{MH}$ as evident in $\mathrm{r}_{\operatorname{tmax}}=0.50$. The overall study indicated that Magnesium hydroxide didn't affect the different physical parameters of plain tablet rather it in certain quantity while present in some batches assisted rapid disintegration and release profile of active content Diclofenac sodium. The DS-MH plain tablet to provide rapid disintegration, dissolution and absorption hence fastest antiinflammatory action with acid neutralizing benefits by $\mathrm{MH}$, might be considered sincerely

Key words: Diclofenac Sodium; Magnesium Hydroxide; Disintegration; Dissolution

J Bangladesh Soc Physiol. 2007 Dec;(2): 42-48.

For author affiliations, see end of text.

http://www.banglajol.info/index.php/JBSP

\section{Introduction}

heumatoid arthritis and other
inflammatory disorders have worldwide
significance. Osteoarthritis causes up to

$10 \%$ of adult population and inflammatory arthropathies about 2-3\%. These diseases are responsible for up to $30 \%$ of physical disabilities and $60 \%$ of the burden of severe disabilities ${ }^{1}$. Rheumatic disease affects the people of all ages and ethnic groups. In UK, more than $40 \%$ over the year 65 have some kind of rheumatic disease, and 20 million people experience rheumatic complaints in each year. The NSAIDs, corticosteroids, opioiod analgesic, chloroquine, penicillamine, gold salt, sulphasalazine are major drugs for antiinflammatory and analgesic action. Costicosteroids are highly selective but have adverse; osteoporosis, fluid retention, dermis arthropaties effect and increases susceptibility to infection. Dyspepsia, gastric or peptic ulceration induced by NSAIDs limit their use. Thus searching for better GI-safe agents were continued and once succeeded to popular COX-2 inhibitors. Merck, the Rofecoxib manufacturer, in September 2004, withdrew the popular new anti-inflammatory drug Rofecoxib after a study that long-term use of these drugs doubled the risk of heart attack and stroke. Thus, 
exploration of safer anti-inflammatory drugs yet to be continued. Diclofenac sodium, one of the earliest NSAIDs member and first drug of phenyl acetic acid series has a wide range of therapeutic utility. It is the highly prescribed drug and has $30 \%$ prescription coverage from all NSAIDs market. It is used to treat osteoarthritis, rheumatic arthritis, chronic juvenile arthritis, low back pain, ankylosing spondylitis, post operative pain, renal pain, and pain in dental and other surgical operation. Diclofenac inhibits synthesis of prostaglandin by blocking the non-specific enzyme Cyclo-oxygenase (COX). Like other NSAID it has also GIT related adverse effects. However, bioavailability profile, antiinflammatory dose, therapeutic efficacy and relatively low ulcerogenic effect ${ }^{2}$ (make this agent more suitable to investigate.

Antacids are defined by their neutralizing capacity of $\mathrm{HCl}$ that can bring to $\mathrm{pH} 3.5$ in 15 minutes and are used to anticipate for symptomatic management of pain caused by dyspepsia or ulcer, reflux oesophagitis \& hyperacidity by neutralizing hydrochloric acid. Hydroxide of $\mathrm{Ca}^{2+}, \mathrm{Al}^{3+} \& \mathrm{Mg}^{2+}$ are relatively insoluble. Thus gastric $\mathrm{OH}^{-}$ion doesn't accumulate to corrosive level. $\mathrm{MH}$ reacts comparatively rapid with $\mathrm{H}^{+}$, and Aluminum hydroxide is relatively slow. Presence of food elevates $\mathrm{pH}$ to above 5.0 after one hour and prolongs the neutralizing effect for 2.0 hours. In general sufficient antacids maintain $\mathrm{pH} 4.0$ in adequate therapy. Partial neutralization of gastric $\mathrm{HCl}$ increases the peptic activity of enzyme four times more in $\mathrm{pH} 2.0$ than at $\mathrm{pH}$ 1.3. Commercial milk of magnesia contained $390 \mathrm{mg} \mathrm{Mg}(\mathrm{OH})_{2}$ per $5 \mathrm{ml}$ have $14 \mathrm{meq}$ acid neutralizing capacity. Moreover antacid in very low dose $(88 \mathrm{mmol}$ per day) for 8 weeks was as effective as $800 \mathrm{mg}$ of Cimetidine in healing ulcers ${ }^{3}$.

To overcome the problems associated with NSAIDs related peptic ulcer and their life threatening complications prophylactic antiulcerant eg missoprostol, $\mathrm{H}_{2}$-receptor blockers, proton-pump inhibitors had been used since before ${ }^{4}$. Antisecretory dose of prostaglandin analogue such as misoprostol, abraprostil, enprostil and risoprostil have shown to be more effective than placebo but costly \& less effective than $\mathrm{H}_{2}$-antagonist ${ }^{5}$. The antisecretory actions of Famotidine and Cimetidine have weak androgenic effect and hence Gynecomastia, impotence ${ }^{6}$ lessened the interest for these agents. Proton pump inhibitors (Omeprazole, Lansoprazole, Pentoprazole, Rabeprazole or Esomeprazole) are being used but are not economic in treating NSAIDs associated hyperacidity. Besides the rebound hyper secretion of widely used omeprazole in about more than $82 \%$ in 15 days post treatment of $\mathrm{H}$ pylori negative patients and maximal basal acid output $28 \%{ }^{7}$ is one of the major objections. Antacids appear to be superior to placebo and equivalent to $\mathrm{H}_{2}$ receptor in releasing ulcers symptom ${ }^{\mathbf{8}, \mathbf{9}}$. $\mathrm{MH}$ as antacid in diclofenac may be one of the best investigational agents in plain tablets.

\section{Methods}

For manufacturing of tablets the BP \& USP specifications were followed. Ethical Drugs (Bangladesh) Ltd. provided the facilities to manufacture as many as the 20000 tablets of different formulation categories sufficient to conduct the study as required quality. Major machines, instruments and reagents used in the experiments are stated in Table: I and II.

Table - I: Depicts instruments used for analysis of various parameters of tablets

\begin{tabular}{ll}
\hline Instruments & Specification of instruments \\
\hline 1. Friabilator & Electro Lab EF (USP) \\
2. Hardness Tester & Pfizer Hardness Tester \\
3. Electronic & Electronic Digital Balance \\
Balance & 4 digit \\
4. $\mathrm{P}^{\mathrm{H}}$ meter & Denver Instruments \\
5. Disintegration & Electro lab \\
$\begin{array}{l}\text { Testing Machine } \\
\text { 6. Dissolution } \\
\text { (USP) Type II }\end{array}$ & ERWEAKA, Germany \\
7. UV- & SHIMADZU UV 1201, \\
Spectrophotometer & UV VIS \\
8. Tablet Compression & City Rotary \\
Machine & Tablet Machine \\
9. Others & Unspecified \\
\hline
\end{tabular}


Table - II: Ingredients, sources, justifications and percent (\%) of ingredients used in different batches of experimental tablets. Per tablet contains same 50 mg diclofenac sodium BP (Square).

\begin{tabular}{llllllll}
\hline Ingredients \& Specification & Justification & Source & \multicolumn{4}{c}{ Quantity of Ingredients } \\
\cline { 3 - 7 } & & & FOI & FO2 & FO3 & FO4 & FO5 \\
\hline Diclofenac sodium (mg) & Active ingredient & Square & 50 & 50 & 50 & 50 & 50 \\
Mg(OH)2 (mg) & Experimental agent & Ethical Drugs & 0 & 200 & 300 & 350 & 400 \\
Povidone USP XXIII (\%) & Granulating agent & BASF, Germany & 3.53 & 1.46 & 1.13 & 1.11 & 1.02 \\
Maize Starch BP 1993 (\%) & Diluents & Paradize, Roquette & 35.34 & 14.64 & 11.33 & 11.07 & 10.17 \\
Lactose BP 1993 (\%) & Diluents & New Zealand & 13.07 & 5.42 & 4.19 & 4.10 & 3.76 \\
Talc Purified BP 1993 (\%) & Lubricant & Local & 2.12 & 0.88 & 0.68 & 0.66 & 0.61 \\
Magnesium Stearate (\%) & Lubricant & Remo Chemicals (BD) Ltd. & 3.53 & 1.46 & 1.13 & 1.11 & 1.02 \\
Avicel PH 101 BP 1993 (\%) & Disintegrating agent & Ming Tai Chemical, Taiwan & 7.07 & 2.93 & 2.27 & 2.21 & 2.03 \\
Magnesium Hydroxide BP (\%) & Experimental agent & Fuji Kasei Co Ltd. Osaka Japan & 00 & 58.57 & 67.95 & 88.59 & 71.21 \\
\hline
\end{tabular}

Preparation of simulated gastric fluid (SGF): The SGF was prepared for $\mathrm{pH}$ 1.2, which was considered equivalent to the gastric environment. Sodium chloride of 2 grams was used against $7.0 \mathrm{ml}$ of $36.4 \% \mathrm{HCl}$ and finally added sufficient distilled water to prepare $1000 \mathrm{ml}$ solution.

Determination of hardness, thickness, friability and weight variation: Crushing strength for hardness was the scale reading to break and was recorded for each time of six tablets and was used for the purpose of hardness test. The Vernier micrometer scale was used to determine the tablet thickness. Roche Friabilator was used to assess the effect of abrasion and shock by utilizing a plastic chamber at 25rpm and accelerated to 100rpm. The difference between the pre and post operation weight were determined after dedusting and the percent changes were recorded. All these operations were conducted as per British Pharmacopoeia 1988. Weight variation was done as per USP specification. Determination of disintegration time: disintegration method type II as per standard USP specification (six glass tube, 3 inches long 10mesh screen) in SGF of pH 1.2 at $37 \pm 2$ 0C was used for this purpose. Construction of calibration curve: A calibration curve was constructed by plotting absorbance at $274 \mathrm{~nm}$ against amount of diclofenac (reference standard) present in $0.1(\mathrm{~N}) \mathrm{HCl}$ solutions ${ }^{\mathbf{1 0}}$. Determination of dissolution rate: USP dissolution calibration was done before starting the experiment. Dissolution test was done at temperature $37{ }^{\circ} \mathrm{C}$ in Rotating Basket1 in solution $0.1 \mathrm{~N} \mathrm{HCl}$, with 50rpm. The solutions were drawn $0 \mathrm{~min} 05 \mathrm{~min}, 10 \mathrm{~min}$, $15 \mathrm{~min}, 30 \mathrm{~min}$, 60min, $75 \mathrm{~min}, 90 \mathrm{~min}$ and $120 \mathrm{~min}$. The spectrophotometric readings were taken for solutions at $274 \mathrm{~nm}$ through Quartz cell. The standard USP XXII/NFXVII apparatus was used for this operation. The dissolution media was used $900 \mathrm{ml}$. The amount of diclofenac sodium was determined as per standard curve constructed.

\section{Results}

In the results, hardness, thickness, friability, weight variation, disintegration time and, dissolution rates are presented in Table - III.

J Bangladesh Soc Physiol. 2007 Dec;(2): 42-48. 
Disintegration and Dissolution of Diclofenac Sodium

Article

Table - III: DS-MH combination preparations and overall evaluation result of the study. * No tablet was found intake after friability test.

\begin{tabular}{lccccc}
\hline Properties & FO1(Control) & FO2 & FO3 & FO4 & FO5 \\
\hline Hardness (Kg) SD ( \pm 1.4$)$ & $1.5-2$ & $6-8$ & $5.5-6.5$ & $4.0-5.0$ & $6.5-8$ \\
Thickness (mm) & 3.50 & 4.00 & 4.90 & 5.60 & 5.90 \\
$(\%)$ Friability & $100^{*} .00$ & 0.11 & 0.62 & 1.14 & 0.05 \\
Weight Variation (\%)SD ( \pm 0.5$)$ & 0.20 & -1.40 & -3.10 & -0.30 & -4.00 \\
Disintegration time (DT) (min) $( \pm$ SD) & $25.24( \pm 5.08)$ & $42.38( \pm 3.19)$ & $6.27( \pm 1.07)$ & $2.04( \pm 0.06)$ & $4.88( \pm 2.28)$ \\
\% Dissolved (30 min) $( \pm S D)$ & $68.92( \pm 0.54)$ & $60.00( \pm 4.55)$ & $84.78( \pm 0.54)$ & $90.38( \pm 4.67)$ & $58.36( \pm 3.47)$ \\
tmax (min) & 25 & 87.5 & 36.67 & 52.55 & 85 \\
\hline
\end{tabular}

Table - IV: Average disintegration time (minutes) of different batches with six individual tablets and standard deviations

\begin{tabular}{|c|c|c|c|c|c|c|c|c|}
\hline \multirow[b]{2}{*}{ Formulation } & \multicolumn{7}{|c|}{ Average DT (min) of 6 tablets } & \multirow[b]{2}{*}{ SD } \\
\hline & 1 & 2 & 3 & 4 & 5 & 6 & Average DT (min) & \\
\hline FO1 & 20.35 & 21.23 & 23.38 & 24.89 & 27.53 & 34.15 & 25.26 & 5.06 \\
\hline FO2 & 38.06 & 39.11 & 42.89 & 43.33 & 44.67 & 46.22 & 42.38 & 3.18 \\
\hline FO3 & 4.88 & 5.47 & 5.98 & 6.44 & 6.99 & 7.87 & 6.272 & 1.07 \\
\hline FO4 & 1.94 & 2 & 2.06 & 2.06 & 2.06 & 2.11 & 2.038 & 0.06 \\
\hline FO5 & 2.8 & 3.55 & 3.82 & 4.94 & 6.57 & 7.82 & 4.917 & 1.93 \\
\hline
\end{tabular}

The average thickness values of each tablet for five formulations were $3.5 \mathrm{~mm}$ (Control), $4.0 \mathrm{~mm}, 4.9 \mathrm{~mm}, 5.6 \mathrm{~mm}$, and $5.9 \mathrm{~mm}$. Hardness data are 1.5-2.0kg (control, FO1), and 6-8kg, 5.5-6.5kg, 4.0-5.0kg, and 6.5-8kg for tablets of batches FO2, FO3, FO4, and FO5 respectively. Losses on friability are $0.11 \%, 0.62 \%, 1.14 \%$, and $0.05 \%$ from four experimental formulations and $100 \%$ tablets were friable in case of control (FO1). Disintegration time $( \pm \mathrm{SD})$ were 25.24 minutes $( \pm 5.08), 42.38$ minutes $( \pm 3.19)$, 6.27 minutes $( \pm 1.07), 2.04$ minutes $( \pm 0.06)$, and 4.88minutes ( \pm 2.28 ) for tablets of batches FO1, FO2, FO3, FO4, and FO5 respectively. J Bangladesh Soc Physiol. 2007 Dec;(2): 42-48.
Dissolution rates $( \pm \mathrm{SD})$ at 30 minutes were $68.9 \%( \pm 0.54), 60.0 \%( \pm 4.55), 84.78 \%( \pm 0.54)$, $90.38 \%( \pm 4.67)$ and $58.36 \%( \pm 3.47)$ of the five batches. In the Table - IV, the Disintegration times (DT) for each 6 tablet of different batches were shown.

In the Table- $\mathrm{V}$, a profile of average dissolution rate at time interval 10, 15, 20, and 30 minutes are mentioned. Within 10 minutes, $71.85 \%$ DS was released from the formulation FO3 and 52.68\% from FO1 (control), 27.15\% from FO2, 28.51\% from FO5. The release rate increase gradually with time and becomes maximum at 30 minutes. 


\section{Article}

Table - V: Dissolution rate (\%) in simulated gastric fluid ( $0.1 \mathrm{~N} \mathrm{HCl}$ solution) of DS tablet at 10 to 30 minutes for different batches of tablets. The table also shows the correlation between changes of time with increasing \% of release of active drug DS.

\begin{tabular}{|c|c|c|c|c|c|}
\hline \multirow[b]{2}{*}{$\begin{array}{l}\text { Time } \\
\text { (min) }\end{array}$} & \multicolumn{5}{|c|}{ Formulations } \\
\hline & FO1 & FO2 & FO3 & FO4 & FO5 \\
\hline 10 & 52.68 & 27.15 & 71.85 & 28.51 & 36.55 \\
\hline 15 & 68.16 & 33.33 & 74.73 & 86.2 & 32.85 \\
\hline 20 & 74.77 & 39.89 & 73.08 & 73.13 & 42.89 \\
\hline 30 & 68.92 & 59.87 & 84.78 & 90.38 & 58.36 \\
\hline r & & 0.1319 & 0.3952 & 0.7249 & 0.5394 \\
\hline
\end{tabular}

Figure-1 shows FO1, the dissolution rate was below than that of FO2, where each tablets of FO1 contains 200mg $\mathrm{Mg}(\mathrm{OH})_{2}$ and FO1 contains no. The dissolution rate decreases in FO3 and FO4 that contains 300mg and 350mg $\mathrm{Mg}(\mathrm{OH}) 2$ respectively.

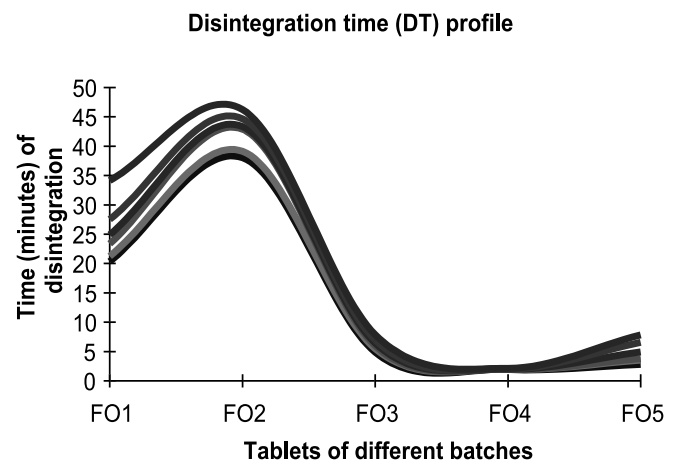

Figure - 1: Average disintegration time of 1 to 6 diclofenac magnesium hydroxide tablets of five different batches.

Figure-2 shows the trend line that indicates lowest DT with maximum $\mathrm{MH}$ and vise versa. The dissolution rate of DS at different time period was determined and presented in Table - IV.
Disintegration and Dissolution of Diclofenac Sodium

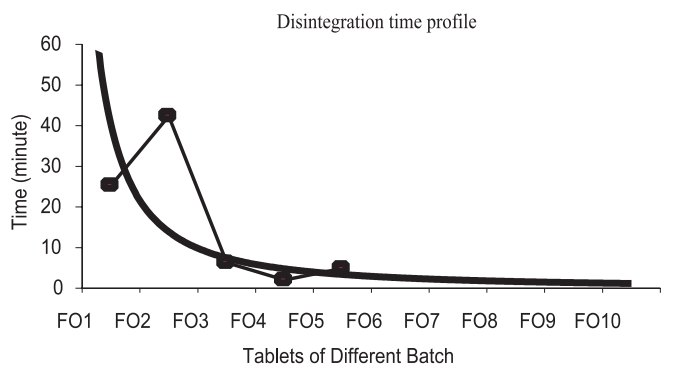

Figure - 2: Trend line of disintegration time of diclofenac magnesium hydroxide plain tablets

Figure-3 is the schematic presentation for 6 formulations between \% DS dissolved in SGF with times (min).

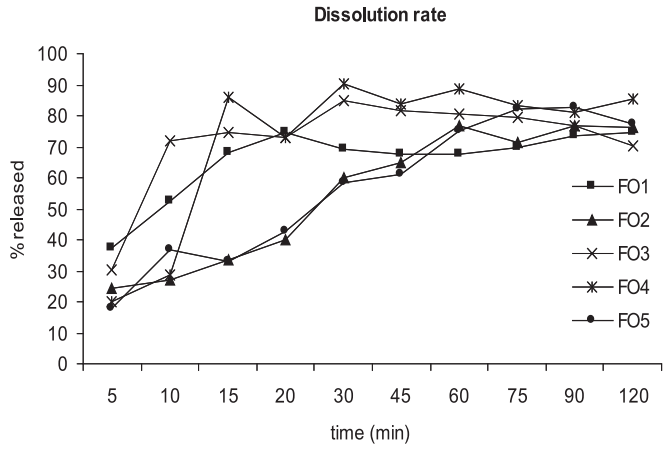

Figure - 3: Dissolution rate (\%) diclofenac sodium from uncoated diclpfenac-antacid plain tablet : figure depicts the release rate (\%) of diclofenac sodium at time 05 minutes, 10 minutes, 15 minutes, 20 minutes, 30 minutes, 45 minutes, 60 minutes, 75 minutes, 90 minutes, and 120 minutes.

\section{Discussion}

With the increment of any agent the average diameter (thickness) of tablet will be increased; thus average thickness increased $0.5 \mathrm{~mm}, 1.4 \mathrm{~mm}$, $2.1 \mathrm{~mm}$ and $2.4 \mathrm{~mm}$ where $\mathrm{MH}$ increased in 200mg, 300mg, 350mg and 400mg in batches FO2, FO3, FO4 and FO5 respectively, it is rationale. A perfect positive correlation (r@1.0) between the changes of quantity of $\mathrm{MH} \&$ average diameter $(\mathrm{mm})$ of per tablet indicated

J Bangladesh Soc Physiol. 2007 Dec;(2): 42-48. 
no variation of excipients present in batch-tobatch preparation. With the addition of $\mathrm{MH}$, hardness increased (table 3) that indicated the binder quality of MH.. A strong negative correlation ( $\mathrm{r}=-0.9$ ) exists between the friability and dissolution rate of this study explains that the higher the rate of friability, the lower is the rate of dissolution. A correlation exists between friability, hardness and in-vitro dissolution rate ${ }^{11}$. And release characteristics vary considerably among different manufacturers and that even identical formulation. MH might have a positive impact on hardness and in our study it is evident by $\mathrm{r}=0.49$, calculated between the hardness and disintegration time (Table-III). With time the rate of dissolution increases in SGF. Strong positive correlation $(r=0.725)$ between changes of time and rate (\%) of release (Table-V) was observed in formulation FO4, containing 350mg experimental agent indicates the excellent combination of $\mathrm{Mg}(\mathrm{OH})_{2}$ and starch . Levy \& Hayes ${ }^{12}$ stated that certain tablet formulations and processing factors apparently affect the dissolution rate of drug contained in the tablets. The DT $42.4 \mathrm{~min}( \pm 3.18)$, of FO2 is beyond the limit of standard specification which indicates poor combination of DS-MH. Average disintegration time was minimum and highly precise among the six tablets for batch FO4, as we see a sharp line in Figure-1 and parallel to $\mathrm{x}$ axis (time-line) in Figure-3. The trend line of DT (Figure-2) shows that upon addition of $\mathrm{MH}$ disintegration time reduced dramatically. The trend line when is extrapolated prospectively to further formulations as shown up to 10 batches in Fig-2, considering the addition of rationale quantity of $\mathrm{Mg}(\mathrm{OH})_{2}$; the DT value (min) wouldn't be increased. Starch is typically used in a concentration $5 \%$ to $20 \%$ of the tablet weight and as a convention starch $5 \%$ as disintegrating agent is recommended; and If rapid disintegration is desired this amount may be increased 10 or $15 \%{ }^{13}$. The starch contents in our test products were within the range of $10-14.6 \%$ in the four batches. As $\mathrm{Mg}(\mathrm{OH})_{2}$ quantity increases the overall weight increases and thus, \%age of starch is reduced (Table-II). Among tablets in this study with $10-11 \%$ starch showed excellent DT profile, that are present in FO3, FO4, and FO5 batches. Moreover, size of the tablets exposed to GSF may have contributory role in reduction of disintegration time of the three batches as with increasing size the exposing surface area increases. From the data stated in Table- $\mathrm{V}$ it is evident that because of $\mathrm{MH}$ in any quantity, the dissolution rates were not affected rather then improvement (Figure-3). The rate of absorption and availability of many drugs that are administered orally in solid forms are the functions of their rate of dissolution in gastrointestinal fluids ${ }^{14,15}$. The drug moieties, which are acidic in nature, absorb better in upper GIT 16 but one should not automatically expect a correlation between the disintegration time and dissolution rate and absorption through biological membrane. The researches conducted earlier demonstrated the possible variation of in-vitro dissolution of drug when composition of dosage form were altered $17,18,19$. This study showed diversified results but some were very much potential. It is established that the surface area of stomach is small compared to intestine (200m2), however some enteric coated preparation may resist dissolution in the intestine and very little portion of the drug is absorbed in gastric zone ${ }^{20}$. But release of active drug content at gastric zone instead of intestine will definitely provide additional area for absorption. Moreover, as of $\mathrm{pH}$ partition hypothesis ${ }^{21}$ acidic drugs in acidic $\mathrm{pH}$ is favored the absorption; this is because of the fact that unionized portion of acidic drug will be predominating.

Diclofenac sodium is an acidic drug of pKa 4.0, and it is predicted that it will have favorable bioavailability profile if released at gastric zone. The standards limits of specification mentioned in this presentation indicate USP ${ }^{22}$. 


\section{Article}

Conclusion

Not all, some DS-MH preparations of this study were potential and indicated that $\mathrm{MH}$ was the key players in improving the disintegration time dissolution profile. The excellent DT profile of batch FO4 having 50mg DS with 350mg MH should be one of the best candidates for further study.

However the formulation approach 'Diclofenac sodium - Magnesium hydroxide’ (DS-MH) plain tablet with the intention to early disintegration and dissolution of active Diclofenac sodium, in gastric zone to provide rapid absorption hence fastest anti-inflammatory action with acid neutralizing benefits by $\mathrm{MH}$, might be considered sincerely. Further, bioequivalence studies may be necessary for commercial standpoint.

\section{Acknowledgement}

We are grateful to Professor Amjad Hossain, Professor Dr Rezaul Jalil, Mr Diderae Alam Mohsin and Professor Abdul Motaleb. My sincere gratitude to the Managing Director of the IBN SINA Pharmaceutical Industry Ltd and $\mathrm{Mr}$ M Mahbubul Karim, former Plant Manager, Novartis (Bangladesh) Ltd., Mr Md Rahamat Ullah, Managing Director, Ethical Drugs (Bangladesh) Ltd for providing the production and analytical lab facilities.

\section{Authors Affiliations}

* 1. Md Mosharaf Hossain Miazi, Assistant Professor, Department of Pharmacy, Northern University Bangladesh, Dhaka, Bangladesh, Cell phone: 01710898878, Fax: 9135562; email: miazi100@yahoo.com

2. M Mohiuddinn A Choudhury, Professor, Department of Pharmacy, University of Science \& Technology, Chittagong, Bangladesh

3. Dr M Habibur Rahman, Professor of Pharmaceutics \& Pharmaceutical Technology, Faculty of Pharmacy, University of Dhaka, Bangladesh

4. Dr Abedur Rahman, Lecturer, Department of Physiology, Dhaka Medical College, Dhaka, Bangladesh

* For correspondence
Disintegration and Dissolution of Diclofenac Sodium

\section{References}

1. Dieppe P. In Oxford Text Book of Medicine, $3^{\text {rd }}$ edition, Oxford Medical Publication, 1996:2943

2. Shen TY. In Burgers' Medicinal Chemistry $4^{\text {th }}$ ed, John Wiley \& Sons, New York, 1979;1205-1336

3. Zaterka S. Very Low dose antacid in the treatment of duodenal ulcers. Digest. Dis and Sci, 1991;36:10

4. Cullen D. Bardhan KD, Eisner M, Koghut DG, Peacock RA, Thompson JM, Hawkey CJ. Primary GastroDuodenal Prophylaxis with Omeprazole for NSAIDs users; Gastroenterol;1996;110:A86

5. David YG. In: The Text Book of Medicine $20^{\text {th }}$ ed, W.B. Saunders Company, 1996: 669

6. Peterson J, Wormsely KG, Medical Toxicol.1996;1:192

7. Derek G, Angela A, Wirz JE, Ardill and Kenneth EL. Rebound hyper-secretion after omeprazole and its relation to on-treatment acid suppression and Helicobacter pylori status. Gastroenterol, 1999; $116: 239$

8. Porro GB, Parente F, Antacid for duodenal ulcer current role, Rheumatoid arthritis and osteoarthritis: Scand J Gastroenterol. 1990;25:48

9. Hunter JO, Walker RJ. Ibid 1991;265

10. Monnujan N, Effect of antacid tablet on invitrodissolution of diclofenac sodium from its enteric release dosage form, Project report BPharm, Jahangirnagar University, 1993a;28-32.

11. Bertocchia P, Antoniellaa E, Valvoa L, Alimontia S and Memolib A. Diclofenac sodium multisource prolonged release tablets - a comparative study on the dissolution profiles, 2005;37(4)679-685

12. Levy G, and Hayes B A. New Eng J Med. 1960;262:1053.

13. Lachman L, Herbert A, Joseph L. Theory and Practice of Industrial Pharmacy, $3^{\text {rd }}$ edition, 328

14. Nelson E, and Schaldemose I. This Journal; 1959,48:489

15. Levy G. Ibid. 1961;5:88

16. Gilbert SB, and Anderson NR. In: The Theory and Practice of Industrial Pharmacy, by Leon Lachman and Herbert A. Libermann Joseph L. Kang $3^{\text {rd }}$ ed, Varghese Publishing House, 1987;336

17. Morrison A, and Campbell J. J Pharm Sci. 1965;54:

18. Wagner. Ibid. 1961;50:359

19 Wagner, Drug Intel, 1969;6:198

20. Goodman \& Gilman's, The Pharmacological Basis of Therapeutics $10^{\text {th }}$ Ed, McGill Medical Publishing Division, 2001:6

21. Shore PA, Brodie BB, and Hogben CAM. The Gastric Secretion of Drugs: A pH Partition Hypothesis, J Phcol Exp Therap. 119, 361-369

22. United States Pharmacopoeia XXII \& National Drug Formulary XVII, 1990.

J Bangladesh Soc Physiol. 2007 Dec;(2): 42-48. 